\title{
Editorial: Millionaires' Row - Revenue management in the year 2109
}

It is 2109 and your vacation is out of this world - quite literally as you are spending a weekend away viewing earth from the moon, watching earth rise over an eerie landscape of lunar craters and peaks.

Is this your imagination or is it reality? The world of space tourism is another application for revenue management. The demand for space travel is real and so is the supply - the Russian space agency already offers package deals to those who have millions to spare and a sense of adventure. In 2001, US businessman Dennis Tito became the first space tourist, paying a reported $\$ 20 \mathrm{~m}$ for a place on a Russian Soyuz rocket that docked with the International Space Station.

Tourism in space, that 'final frontier', is more likely to happen than not. Over 30 years ago, Pan American Airlines began taking reservations for a commercial space flight to the moon. Over 90,000 people made a reservation for such flight, including Ronald Reagan. Pan Am's space flight promotion in those early days was a marketing gimmick, based upon the film 2001: A Space Odyssey, which was a hit in the cinemas in 1968.

The US Department of Defense's space programme thinks commercial flights at around $\$ 15,000$ are feasible in the next decade (Sample, 2002). The department, not wanting to miss out on a money spinning opportunity, used a 1995 survey that asked people how much they would be willing to pay for a ticket into space. From this they estimated that a price tag of around $\$ 15,000$ a ticket would pull in about a million passengers a year. They then worked out how to bring the price per flight down to this level. They found that the cheapest and quickest way to get lots of people into space and back would be to develop a two-stage shuttle system. The first stage resembles a short, fat rocket with wings. This takes a smaller winged rocket to the edge of space, where it fires up its own motors to push it into Earth orbit. The first stage glides back down to Earth to be refuelled for another launch. Meanwhile, the second stage docks with an orbiting space station, unloads its passengers, and collects previous passengers from the space station for the return trip.

Further studies (Penn, 2003) suggest that a viable space tourism industry will require flight rates about two orders of magnitude higher than those required for conventional spacelift. Although enabling round-trip cost goals for a viable space tourism business are currently about $\$ 240 /$ pound $(\$ 529$ / $\mathrm{kg}$ ), or $\$ 72,000 /$ passenger round-trip, the studies suggest the goals should be about $\$ 50 /$ pound $(\$ 110 / \mathrm{kg})$ or approximately $\$ 15,000$ for a typical passenger and baggage. The lower price would probably open space tourism to the general population. Vehicle reliabilities must approach those of commercial aircraft as closely as possible.

Organisations such as the MirCorp (Klerkx, 2003) have been formed to commercialise the Mir Space Programme. Mir is already planning a space hotel, a sort of mini-MIR space station, while US companies like SPACEHAB plan 'hubs in space' that will serve as destinations for paying visitors. Even Hilton Hotels in the 1960s had plans for a terrestrial hotel chain, a Lunar Hilton and an Orbiter Hilton. The Lunar Hilton would be located below the lunar surface and have rooms for 100
Journal of Revenue and Pricing Management, Vol. 2, No. 3, 2003,

pp. 197-198
(C) Henry Stewart Publications, 1476-6930 
guests; the Orbiter Hilton would be somewhat smaller.

Space tourism may not happen in my lifetime, but I can still dream about it. There is a little bit of Captain Kirk and Star Trek in us all.

\section{RESEARCH PAPERS}

Oded Lowengart and colleagues' paper shows us how a reference price can be set by retailers in order to maximise their utility, given two consumer characteristics, ie the level of loyalty and sensitivity to quality variations, and one structural variable, brand proliferation. Jochen Wirtz and coauthors explore the issue of conflict between customers and long-term pricing destinations within the field of revenue management. The paper suggests a number of strategies that can be used to resolve such conflicts.

\section{PRACTICE PAPERS}

Brent Lippman demonstrates how revenue management is used in the grocery industry, describing in detail how such retailers apply and gain benefit from such a strategy. David Hassan discusses some of the issues facing revenue management in the airline industry and the challenges the industry is facing. Sid Frank's paper highlights Six Sigma's approach to revenue management and pricing, providing an insight into a methodology that has a proven track record. Jon Manning's paper examines the growing trend towards proliferation of surcharging, where it is prac- tised and what the pros and cons are. This is the practice of removing hidden costs and making them visible or charging customers for new expenses associated with being in business. Bernard Rannou and Delfo Melli's article describes a method to measure the performance of revenue management through a scientific programme.

\section{FUTURES AND REVIEWS}

Stowe Shoemaker enlightens us with a look at customer loyalty and the future of pricing. This thought-provoking paper gives a comprehensive overview of customer loyalty with a direct connection to revenue management. Basically, the paper asks us to think of new ways of both pricing services and presenting these prices to our consumers. The goal is to have consumers believe that the firm is truly looking after the customer's best interest. Tony Ingold reviews Nawal Tangeja's new book, Airline Survival Kit: Breaking Out of the Zero Profit Game. Finally, Tim Rosen offers us his thoughts about a new 'Revenue Management Club' that has just started up in London.

\section{References}

Klerkx, G. (2003) 'The High Life', New Scientist, 30th August.

Penn, J.P and Lindley, C.A. (2003) 'Requirements and Approach for a Space Tourism Launch System', Acta Astronautica, 52, 1, 4975.

Sample, I. (2002) 'Space Tourism Viable at $\$ 15,000$ at Seat', New Scientist, 31st October. 